\title{
PENGARUH PEMBELAJARAN TEAM GAMES TOURNAMENT TERHADAP KECERDASAN EMOSIONAL SISWA
}

\author{
Ratih Handayani ${ }^{1}$ \\ ${ }^{1}$ Program Studi Pendidikan Matematika, STKIP Muhammadiyah Kotabumi \\ email: ratihinan@gmail.com
}

\begin{abstract}
This quasi experiment research was aimed to find outthe influence of interaction between cooperative learning of TGT and gender on the seventh grade of SMPN 4 Kotabumi students' emotional intelligence. The research population was all of the seventh grade of SMPN 4 Kotabumi students in academic year 2016/2017 consisting of 163 students with the research sample of VIIA class as the experimental class taught by cooperative learning of TGT and VIIB class as the control class taught by using direct teaching and learning model. Meanwhile, the instruments used were questionnaire was used to collect the data of students' emotional intelligence. The data analysis was done by t-test with the help of SPSS 20 after it was found that the data were normal and homogenous through normality and homogeneity test. Based on the research result, some conclusions were made as follows there is interaction influence between cooperative learning of TGT and gender on the seventh grade of SMPN4 Kotabumi students' emotional intelligence
\end{abstract}

Key Words: Influence, Cooperative Learning of TGT, Student's Emotional Intelligence.

\section{A. PENDAHULUAN}

Sebagai ujung tombak kurikulum dalam pembelajaran, seorang pendidik harus memiliki kiat agar siswa dapat belajar dengan efektif dan mencapai tujuan pembelajaran. Terlebih pada siswa Sekolah Menengah Pertama (SMP) yang pada dasarnya mempunyai kemampuan berpikir abstrak yang belum sempurna. Berdasarkan pengamatan, siswa SMP belum memiliki kelancaran dalam berkomunikasi dengan orang lain terlihat dari ketidakberanian siswa dalam mengemukakan pendapat, takut menerima kritikan, gugup bila bicara dengan orang lain yang belum dikenal, kemampuan bekerja sama yang belum baik dan sebagainya. Hal tersebut menjadi dasar bahwa dalam mengatur emosinya, siswa SMP masih mengalami kesulitan atau bisa dikatakan kecerdasan emosionalnya masih lemah.

Kecerdasan emosional menurut Goleman (2000:44) mempengaruhi kesuksesan seseorang sebesar $80 \%$ yakni kemampuan memotivasi diri sendiri, mengatasi frustasi, mengontrol desakan hati, mengatur suasana hati (mood), berempati serta kemampuan bekerja sama sedangkan $20 \%$ sisanya disumbang oleh 
kecerdasan intelektual.

Oleh karena itu, salah satu kemampuan yang harus dimiliki oleh seorang guru adalah penguasaan model pembelajaran yang bervariasi yang mampu mempermudah siswa dalam memahami materi pelajaran serta meningkatkan kecerdasan emosional siswa. Salah satu materi pelajaran yang harus dikuasai siswa adalah materi pelajaran matematika. Matematika sebagai salah satu mata pelajaran yang diselenggarakan di sekolah memberi peranan penting dalam mewadahi siswa untuk memiliki kemampuan berpikir analitis, kreatif, logis, sistematis, evaluatif serta argumentatif yang dapat digunakan untuk memecahkan suatu permasalahan dalam bidang matematika atau dalam bidang lain dalam kehidupan sehari-hari.

Rendahnya kecerdasan emosional siswa dapat mengakibatkan rendahnya hasil belajar matematika siswa. Oleh karena itu diperlukan perbaikan pada proses pembelajaran misalnya memberikan alternatif model pembelajaran yang mampu meningkatkan pemahaman konsep matematika dan kecerdasan emosional. Model pembelajaran kooperatif yang diperkirakan mampu meningkatkan pemahaman konsep matematika dan kecerdasan emosional adalah Model Pembelajaran Kooperatif Teams Games Tournaments (TGT).

Teams Games Tournaments (TGT) adalah sebuah model manajemen kelas dimana para siswa ditempatkan dalam tim dengan kemampuan yang heterogen untuk berkompetisi dalam sebuah permainan. Menurut Slavin dalam Meg O’Mahony (2006), TGT dapat meningkatkan kemampuan dasar, prestasi belajar siswa, interaksi positif antar siswa, penerimaan keanekaragaman teman sekelas, dan kepercayaan diri. Pada model pembelajaran ini siswa menjadi siap dan berusaha untuk memahami dan menguasai materi dalam proses pembelajaran dan melatih siswa untuk bekerjasama dengan baik dengan anggota kelompoknya dalam menjawab tugas yang diberikan oleh guru. Dengan demikian TGT diharapkan dapat mempengaruhi kecerdasan emosional siwa.

Pada pembelajaran TGT diharapkan siswa lebih tertarik dengan materi pelajaran karena pelajaran disampaikan dengan cara yang lebih menyenangkan dan menarik. Selain itu dengan turnamen di akhir pembelajaran, siswa akan belajar bagaimana menerima kekalahan dan menghargai kemenangan. Maka secara tidak langsung TGT dapat meningkatkan kecerdasan emosional siswa.

Dalam penelitian Johnson dan Wang (2003) menjelaskan bahwa siswa dengan kecerdasan emosional yang baik mampu untuk menyalurkan ulang pikiran negatif dan perasaan terkait dengan emosi negatif 
tersebut menjadi perilaku adaptif (misalnya, menghabiskan lebih banyak waktu pada persiapan ujian) sehingga mereka mampu menjaga kestabilan emosinya untuk tetap berhasil dalam tes yang mereka lakukan

Berdasarkan uraian tersebut dan penelitian sebelumnya maka dalam penelitian ini yang dikaji adalah pengaruh model pembelajaran kooperatif TGT terhadap kecerdasan emosional siswa kelas VII SMP Negeri 4 Kotabumi.

Berdasarkan rumusan masalah di atas, maka tujuan penelitian ini adalah untuk mengetahui adakah pengaruh model pembelajaran kooperatif TGT terhadap kecerdasan emosional siswa.

\section{B. KAJIAN TEORI}

Sebelumnya kecerdasan intelektual (IQ) dianggap sebagai satu-satunya faktor yang dapat menghantarkan individu pada keberhasilan, tetapi dalam kenyataannya tidak semua dapat dipecahkan dengan pendekatan rasional sebagai produk berpikir. Henson dan Ben (1999:78) mengatakan sifat-sifat emosional dan sosial yang orang perlihatkan merupakan hasil pengalaman dengan orang lain melalui kehidupan berupa pikiran, perasaan sikap, dan keterampilan. Sifat emosional ini terlihat bagaimana sikap seseorang dalam memperlakukan orang lain. Keadaan seperti ini berlaku dalam proses pembelajaran di kelas, siswa yang memperlihatkan tingkah laku prososial dirasakan oleh guru dan siswa lainnya.

Agustian (2001:56) menyatakan bahwa kecerdasan emosi adalah kemampuan mendengarkan dan berkomunikasi lisan, adaptasi, kreatifitas, ketahanan mental terhadap kegagalan, kepercayaan diri, motivasi, kerja tim, dan keinginan untuk memberi konstribusi terhadap keberhasilan. Selanjutnya, Mustaqim (2004:152) menyatakan lima unsur kecerdasan emosi dapat diuraikan sebagai berikut.

a. Kesadaran Diri (self-awareness)

(1) Kesadaran emosi (emotional awereness), mengenal emosi diri sendiri dan efeknya.

(2) Penilaian diri secara teliti (accurate self-assessment), mengetahui kekuatan dan batas-batas diri sendiri.

(3) Percaya diri (self-confidence), keyakinan tentang harga diri dan kemampuan sendiri.

b. Pengaturan diri (self-regulation)

(1) Mengendalikan diri (self control), mengelola emosi dan desakan diri.

(2) Sifat dapat dipercaya (trust worthness), memelihara norma kejujuran dan integritas.

(3) Kehati-hatian (counciousness), bertanggung jawab atas kinerja pribadi.

(4) Adaptabilitas (adaptability), keluwesan dalam menghadapi perubahan.

(5) Inovasi (innovation), mudah menerima dan terbuka terhadap gagasan, pendekatan dan informasiinformasi baru.

c. Motivasi (motivation)

(1) Dorongan prestasi (achievement 
drive), yaitu dorongan untuk lebih baik atau memenuhi standar keberhasilan.

(2) Komitmen (commitment), yaitu kemampuan menyesuaikan diri dengan sasaran kelompok atau lembaga.

(3) Inisiatif (initiative), yaitu kesiapan untuk memanfaatkan kesempatan.

(4) Optimisme (optimism), yaitu kegigihan dalam memperjuangkan sasaran kendati ada halangan dan kegagalan.

\section{d. Empati (emphaty)}

(1) Memahami orang lain (understanding others), yaitu mengindera perasaan dan per-spektif orang dan menunjukkan minat aktif terhadap kepentingan mereka.

(2) Mengembangkan orang lain (developing others), merasakan kebutuhan perkembangan orang lain dan berusaha menumbuhkan mereka.

(3) Orientasi pelayanan (service orientation), yaitu kemampuan mengantisipasi, mengenal dan berusaha memenuhi kebutuhan orang lain.

(4) Memanfaatkan keragaman (leveraging diversity), kemampuan menumbuhkan peluang melalui pergaulan dengan orang lain.

(5) Kesadaran politis (political awareness), yaitu kemampuan membaca arus emosi sebuah kelompok dan hubungannya dengan kekuasaan.

\section{e. Keterampilan Sosial (social-skill)}

Berdasarkan uraian tersebut kecerdasan emosional adalah kecerdasan emosional siswa adalah kemampuan siswa mengenal perasaannya sendiri dan perasaan orang lain, kemampuan me- motivasi diri sendiri dan kemampuan mengelola emosi dengan baik pada diri sendiri dan dalam hubungan dengan orang lain. Mengingat luasnya cakupan kecerdasan emosi, maka dalam penelitian ini pembahasan kecerdasan emosional dibatasi dengan kaitannya aktifitas siswa dalam kegiatan proses belajar mengajar, yaitu kesadaran diri (self-awareness), pengaturan diri (self-regulation), motivasi (motivation), empati (emphaty), dan keterampilan sosial (social-skill) dalam kaitannya dengan kegiatan belajar.

Pembelajaran menurut Charlton, Williams, dan McLaughlin (2005:66) akan membuat siswa lebih aktif dan merasa senang untuk belajar jika menggunakan permainan. Pembelajaran akan terlihat lebih menarik jika ketika guru menjelaskan dipadukan dengan permainan sehingga penyampaian materi lebih cepat tersampaikan. Permainan dapat disusun guru dalam bentuk kuis berupa pertanyaanpertanyaan yang berkaitan dengan materi pelajaran. Model pembelajaran TGT memungkinkan semua siswa dapat menguasai materi pada tingkat penguasaan yang relatif sama atau sejajar. Aktivitas belajar dengan permainan yang dirancang dalam pembelajaran kooperatif model TGT memungkinkan siswa dapat belajar lebih rileks disamping menumbuhkan tanggung jawab, kerja sama, persaingan sehat, dan keterlibatan belajar. 
Pembelajaran kooperatif tipe TGT menurut Slavin (2008:164) terdiri dari lima langkah tahapan, yaitu

a. Penyajian kelas

b. Kelompok (tim)

c. Game

d. Turnamen

e. Team recognize (penghargaan kelompok)

\section{METODOLOGI PENELITIAN}

Jenis penelitian ini adalah eksperimen semu (quasi-experimental research). Penelitian ini bermaksud untuk mengetahui pengaruh model pembelajaran kooperatif tipe TGT terhadap kecerdasan emosional. Kedua kelompok dilihat kemampuan awalnya untuk mengukur kondisi awal. Selanjutnya pada kelompok pertama diberi perlakuan $T G T$ dan kelompok kedua diberi perlakuan konvensional. Setelah selesai perlakuan, kedua kelompok diberi tes akhir atau posttest.

Penelitian ini dilaksanakan di SMP Negeri 4 Kotabumi. Populasi dalam penelitian ini adalah seluruh siswa kelas VII SMP Negeri 4 Kotabumi tahun pelajaran 2016/2017 yang terdistribusi dalam 5 kelas. Sampel yang digunakan sebanyak 2 kelas yaitu VII A dan VII B. Sampel dipilih dengan menggunakan teknik random purposive. Instrumen penelitian yang digunakan dalam penelitian ini berupa angket. Angket kecerdasan emosional disusun berdasarkan indikator kecerdasan emosional siswa yaitu self-awareness, self-regulation, motivation, emphaty, dan social skills dengan pernyataan-pernyataan positif dan negatif. Teknik analisis data uji t, dengan prasyarat normalitas dan homogenitas

\section{HASIL PENELITIAN}

Setelah proses pembelajaran selesai, juga dilakukan tes akhir untuk kecerdasan emosional. Selanjutnya akan dilakukan pengujian normalitas untuk data kecerdasan emosional. Pengujian normalitas dilakukan dengan menggunakan uji Kolmogorov Smirnov. Pengolahan data untuk uji normalitas menggunakan bantuan SPSS 20. Hipotesis yang diuji adalah sebagai berikut:

$\mathrm{H}_{0}$ : Sampel berasal dari populasi berdistribusi normal

$\mathrm{H}_{1}$ : Sampel tidak berasal dari populasi berdistribusi normal

Hasil perhitungan uji normalitas data posttest kecerdasan emosional siswa dapat dilihat pada Tabel 1 berikut.

Tabel 1

Hasil Uji Normalitas Data Posttest Kecerdasan Emosional Siswa

\begin{tabular}{ccccc}
\hline & & \multicolumn{3}{c}{$\begin{array}{c}\text { Kolmogorov } \\
\text { Smirnov }\end{array}$} \\
\cline { 3 - 5 } Aspek & Kelas & $\mathrm{s}$ & $\mathrm{N}$ & Sig. \\
\cline { 3 - 5 } & $\begin{array}{c}\text { Pembelajaran } \\
\text { Kooperatif } \\
\text { Kecerdasan } \\
\text { Emosional } \\
\text { tipe TGT }\end{array}$ & 3,87 & 32 & 0,200 \\
& $\begin{array}{c}\text { Pembelajaran } \\
\text { langsung }\end{array}$ & 3,62 & 32 & 0,140 \\
\hline
\end{tabular}


Berdasarkan Tabel 1 tersebut diketahui bahwa taraf signifikansi yang diperoleh melalui uji normalitas Kolmogorov Smirnov pada data posttest kecerdasan emosional di kelas yang menggunakan pembelajaran langsung dan kelas yang menggunakan pembelajaran kooperatif tipe TGT lebih besar dari taraf signifikansi yang telah ditentukan yakni 0,05. Pada kelas yang menggunakan pembelajaran kooperatif tipe TGT diperoleh 0,200 dan pada kelas yang menggunakan pembelajaran langsung sebesar 0,14 . Maka $\mathrm{H}_{0}$ diterima, ini berarti data posttest kecerdasan emosional yang diperoleh pada penelitian ini berdistribusi normal.

Pengujian data berikutnya adalah homogenitasnya. Data yang diperoleh dari angket kecerdasan emosional. Perlu dilakukan pengujian homogenitas terlebih dahulu. Pengolahan data untuk menghitung homogenitas menggunakan bantuan SPSS 20, dimana uji homogenitas menggunakan statistik Levenee. Dengan hipotesis sebagai berikut:

$\mathrm{H}_{0}$ : Tidak terdapat perbedaan varian kedua populasi data (homogen)

$\mathrm{H}_{1}$ : Terdapat perbedaan varian kedua populasi data (tidak homogen)

Hasil uji tersebut dihitung dengan taraf signifikansi 0,05 . Kriteria pengujian adalah tolak $\mathrm{H}_{0}$ apabila Sig. $<0,05$ maka distribusinya tidak homogen dan terima $\mathrm{H}_{0}$ apabila Sig. > 0,05 maka distribusinya homogen. Berdasarkan hasil perhitungan homogenitas dengan menggunakan SPSS 20 diperoleh Uji Statistik Lavene's pada Tabel 2 berikut.

Tabel 2

Hasil Uji Statistik Lavene's Kecerdasan Emosional

\begin{tabular}{|c|c|c|c|}
\hline \multirow[b]{2}{*}{ Aspek } & \multicolumn{2}{|c|}{ Levene } & \multirow[b]{2}{*}{ simpulan } \\
\hline & Kelas & Sig. & \\
\hline $\begin{array}{c}\text { Kecerdasan } \\
\text { Emosional } \\
\text { SIswa }\end{array}$ & $\begin{array}{c}\text { Pembelajaran } \\
\text { Kooperatif tipe } \\
\text { TGT dan } \\
\text { Pembelajaran } \\
\text { langsung } \\
\end{array}$ & 0,087 & $\begin{array}{c}\text { Terima } \\
\mathrm{H}_{0}\end{array}$ \\
\hline
\end{tabular}

Berdasarkan data di atas terlihat bahwa nilai Sig. > 0,05 yaitu 0,087. Ini berarti $\mathrm{H}_{0}$ diterima, artinya tidak terdapat perbedaan varian kedua populasi data.

Sebelum dilaksanakan pembelajaran, baik pada kelas eksperimen maupun kelas kontrol dilihat kecerdasan emosional awalnya yaitu skor yang diperoleh dari angket kecerdasan emosional. Setelah dilakukan pengolahan data kecerdasan emosional awal pada kelas eksperimen dan kelas kontrol diperoleh data sebagai berikut, yang selengkapnya disajikan dalam Tabel 3 berikut

Tabel 3

Rekapitulasi Kecerdasan Emosional Awal

\begin{tabular}{|c|c|c|c|}
\hline No. & $\begin{array}{c}\text { Deskripsi } \\
\text { Data }\end{array}$ & $\begin{array}{c}\text { Kelas } \\
\text { TGT }\end{array}$ & $\begin{array}{c}\text { Kelas } \\
\text { Pemb. } \\
\text { Langsung }\end{array}$ \\
\hline 1 & $\begin{array}{l}\text { Jumlah } \\
\text { Siswa }\end{array}$ & 32 & 32 \\
\hline 2 & Rata-rata & 69,06 & 69,38 \\
\hline 3 & $\begin{array}{l}\text { Standar } \\
\text { Deviasi }\end{array}$ & 6,40 & 5,84 \\
\hline 4 & $\begin{array}{l}\text { Skor } \\
\text { Terendah }\end{array}$ & 53 & 56 \\
\hline 5 & $\begin{array}{l}\text { Skor } \\
\text { Tertinggi }\end{array}$ & 80 & 80 \\
\hline
\end{tabular}


Berdasarkan Tabel 3 terlihat bahwa kecerdasan emosional awal siswa kelas eksperimen dan kelas kontrol tidak jauh berbeda, tampak pada skor terendah, skor tertinggi, rata-rata dan simpangan baku. Maka kedua kelas dapat digunakan untuk penelitian.

Setelah dilakukan proses pembelajaran pada kedua kelas yang digunakan dalam penelitian, dilakukanlah tes akhir pada pertemuan terakhir untuk variabel kecerdasan emosional. Tes akhir diberikan kepada kedua kelas yang digunakan dalam penelitian ini. Butir angket yang diberikan dibuat berdasarkan kisi-kisi yang sesuai dengan indikator kecerdasan emosional dan telah divalidaasi oleh ahli dan telah dihitung validitas empirisnya.

Rekapitulasi data nilai tes akhir kecerdasan emosional siswa disajikan dalam Tabel 4 berikut.

Tabel 4 Rekapitulasi Data Nilai Tes Akhir Kecerdasan Emosional

\begin{tabular}{cccc}
\hline \multirow{2}{*}{$\begin{array}{c}\text { Deskripsi } \\
\text { Data }\end{array}$} & \multicolumn{2}{c}{ Model pembelajaran } & \\
\cline { 2 - 3 } & Kooperatif & Total \\
& TGT & Langsung & \\
\hline $\mathrm{n}$ & 32 & 32 & 64 \\
Mean & 95,81 & 90,22 & 93,02 \\
Maks & 105 & 99 & 105 \\
Min & 86 & 85 & 85 \\
SD & 4,84 & 3,87 & 5,18 \\
\hline
\end{tabular}

\section{E. PEMBAHASAN HASIL PENELITIAN}

Kecerdasan emosional dapat dikembangkan melalui belajar kelompok yang melibatkan interaksi dengan orang lain yang memberikan kesempatan kepada siswa untuk menjelaskan materi kepada temannya, mencari solusi dari suatu permasalahan. Hubungan emosional dapat berkembang dengan baik bila seseorang terbiasa untuk bergaul dengan banyak orang.

Pada kelas dengan menggunakan pembelajaran kooperatif tipe TGT, siswa akan berdiskusi dalam kelompok. Dalam diskusi untuk memecahkan masalah yang diberikan setiap siswa belajar untuk bekerjasama agar semua kelompok dapat menguasai materi pembelajaran, selain itu siswa akan belajar untuk menerima atau menyampaikan pendapat serta menerima perbedaan yang mungkin muncul. Maka secara tidak langsung siswa akan belajar bagaimana mengatur emosinya. Setelah selesai berdiskusi dalam kelompok, siswa akan bermain game. Yaitu siswa sebagai perwakilan kelompok dengan kemampuan sama bermain games dengan cara memilih kartu bernomor dan menjawab pertanyaan yang sesuai dengan nomor tersebut. Pada fase ini siswa akan belajar bagaimana berusaha untuk menang dan mampu menghargai kemenangan serta siswa juga akan belajar bagaimana menerima kekalahan.

Pada akhir pembelajaran siswa membuat kesimpulan yang difasilitasi guru, sehingga terjadi penekanan materi dan siswa akan semakin paham tentang materi yang dipelajari dihari tersebut. Diakhir bab, siswa akan melakukan turnamen, dengan 
cara siswa yang berkemampuan sama akan duduk dalam satu meja yang meja dan berlomba untuk menjawab pertanyaan yang diberikan oleh guru. Pada penelitian ini materi yang diajarkan adalah tentang segitiga dan segiempat.

Pembelajaran TGT sesuai dengan indikator kecerdasan emosional kesadaran diri (self-awareness), pengaturan diri (selfregulation), motivasi (motivation), empati (emphaty), dan keterampilan sosial (socialskill) dalam kaitannya dengan kegiatan belajar.

\section{F. SIMPULAN DAN SARAN}

Berdasarkan hasil penelitian dan pembahasan diperoleh simpulan bahwa terdapat pengaruh model pembelajaran kooperatif TGT terhadap kecerdasan emosional siswa kelas VII SMP Negeri 4
Kotabumi.

Berdasarkan simpulan, agar mendapatkan hasil yang lebih optimal disarankan hal-hal berikut ini.

1. Guru dapat menerapkan model pembelajaran kooperatif tipe TGT sebagai salah satu alternatif untuk meningkatkan kecerdasan emosional siswa.

2. Peneliti lain yang ingin mengembangkan penelitian lanjutan mengenai model pembelajaran kooperatif tipe TGT dan kecerdasan emosional hendaknya melakukan pembiasaan pembelajaran terlebih dahulu dan membuat buku tuntunan guru dan siswa sebagai wadah bagi guru untuk melihat kekurangan maupun perkembangan belajar siswa secara berkelanjutan.

\section{DAFTAR RUJUKAN}

Agustian, Ary Ginanjar. 2004. Kecerdasan Emosi dan Spiritual. Jakarta: Arga.

Charlton, B., Williams, R. L dan McLaughlin, T.F. 2005. Educational Games: A Technique to Accelerate the Acquisition of Reading Skills of Children with Learning Disabilities. International Journal of Special Education. Volume 20, Number 2, page 66-72.

Goleman, D. 2002. Kecerdasan Emosi Untuk Mencapai Puncak Prestasi. (Edisi terjemahan oleh Tri Kantjono Widodo). Jakarta: PT Gramedia Pustaka Utama.

Henson, K.T. \& Ben F.E. 1999. Educational Psychology for Effective Teaching. Belmont, CA: Wadsworth Publishing Company. 
Johnson, M.C. \& Wang, A. 2003. Emotional Intelligence and Academic Performance of College Honors and Non-Honors Freshmen. Journal of the National Collegiate Honors Council, 10(1): 105-114.

Meg, O’Mahony. 2006. Teams-Games-Tournament (TGT) Cooperative Learning and Review. NABT Conference 14 October 2006.

Mustaqim. 2004. Psikologi Pendidikan. Yogyakarta: Pustaka Pelajar.

Slavin, R.E. 2008. Cooperative Learning Teori, Riset dan Praktik. Terjemahan: Nurulita Yusron. Bandung: Nusa Media. 